\title{
Vínculo e constituição da subjetividade ${ }^{1}$
}

\section{Regina Maria Rahmi ${ }^{2}$}

Ao iniciar este trabalho, me veio à lembrança uma frase que me foi oferecida durante uma sessão: "Caminhante, não há caminho, o caminho se faz ao caminhar". Esses versos famosos do poeta espanhol Antonio Machado [1875-1939] foram o mote disparador desta reflexão sobre mal-estar na família e sobre inquietações e perplexidades em nosso caminhar como analistas, quando nos despojamos do já conhecido para aprender a partir do que se apresenta a cada sessão.

A partir da Idade Moderna, o casal se fundou no amor romântico e a família, na reciprocidade de sentimentos nascidos por intermédio do casamento, em laços de ternura e em interdições presentes na relação entre pais e filhos. Criou-se a necessidade de afetividade e intimidade, contribuindo para a dimensão reflexiva que permite ao ser humano poder pensar e falar por si. Assegurando a transmissão da vida psíquica através das gerações, essa nova família fundada em sentimentos íntimos produz a subjetividade que será objeto do estudo de Freud.

Imersa no caldo cultural e social de cada época, a família exerce um papel fundamental na transmissão da cultura, por estabelecer uma continuidade biológica e psíquica entre as gerações. Na clínica devemos estar atentos às reações, às transformações - assim como aos seus significados imaginários - associados ao que seria influência desse contínuo nos vínculos e na constituição da subjetividade.

$\mathrm{Na}$ atualidade, tempos de fluidez e indefinição, observamos com grande frequência a busca do prazer imediato, a evitação do desconforto advindo de qualquer frustração ou postergação que implique dor psíquica. A busca da completude narcísica e a dificuldade de acessar o universo simbólico parecem intensificar-se, assim como as confusões entre o eu e o outro, entre fantasia e realidade, entre o íntimo e o público.

\footnotetext{
${ }^{1}$ Este trabalho foi apresentado na mesa "Mal-estar na família" com Belinda Mandelbaun no I Simpósio Bienal "O mesmo, o outro: Psicanálise em movimento" da Sociedade Brasileira de Psicanálise de São Paulo.

${ }^{2}$ Docente do curso de Psicanalise da Vincularidade de família e casal da Sociedade Brasileira de Psicanálise de São Paulo, coordenadora do curso de especialização Família e Casal na Atualidade no Instituto Sedes Sapientiae.
} 
A constituição do humano se dá a partir de vínculos de continência e interdição vínculos primários de sustentação e acolhimento das necessidades internas e externas do bebê, continência de agonias impensáveis que, a partir de um vínculo, podem ser transformadas e compreendidas. Por outro lado, a função paterna, ou função terceira, abre a possibilidade de descolamento do mundo narcísico para a entrada no mundo simbólico. As dificuldades nesse percurso favorecem regressões narcísicas, negação das diferenças, vínculos endogâmicos que sujeitam seus integrantes por meio de alianças inconscientes nocivas, as quais representam obstáculos à liberdade e à construção da singularidade.

Além disso, a história que precede a constituição da subjetividade e que age de maneira inconsciente é fator primordial na inserção do sujeito em seu próprio tempo e história. A transmissão dessa pré-história familiar pode ocorrer no âmbito de uma mesma geração ou de uma geração a outra. A transmissão intergeracional é estruturante e organizadora do vínculo intersubjetivo. É um espaço de transcrição transformadora (Kaës, 1996) no qual se veicula uma herança constituída pelas fantasias, imagos e identificações, de forma a organizar a história e o relato mítico de cada sujeito. Manifesta-se nas tradições e nas culturas.

Já a transmissão transgeracional abarca acontecimentos traumáticos, aquilo que não pôde ser transformado em palavras; o não elaborado das angústias parentais atravessa a nova geração, invadindo de forma direta de um sujeito a outro, de uma geração a outra, sem preservação de espaços subjetivos. Essa não história que não pôde ser elaborada necessita ser clivada, tendo então o sujeito uma parte de seu psiquismo alienado, estrangeiro de si mesmo. Transmite-se o não simbolizado, herdam-se enigmas, zonas de silêncio e negação; é o território das identificações alienantes que se dão entre os sujeitos, manifestando-se como sentimentos de vazio e fissuras narcísicas.

Em O mal-estar da civilização (1930), Freud faz uma importante ligação entre cultura e subjetividade; dá ênfase ao sofrimento psíquico característico das relações humanas diante da impossibilidade do amor, ou melhor, da impossibilidade de obter total satisfação quando o prazer está ligado à escolha amorosa. De lá para cá, muitos analistas se ocuparam de refletir sobre esse mal-estar, que se manifesta nos vínculos 
afetivos como resposta ao conflito de Eros e Tânatos, construção e destruição, subjetividade e dessubjetivação.

Logo no início daquele texto, Freud escreve:

"No auge do enamoramento, a fronteira entre $\mathrm{Eu}$ e objeto ameaça desaparecer. Contrariando o testemunho dos sentidos, o enamorado afirma que Eu e Tu são um, e está preparado para agir como se assim fosse. [...] [Há casos em que] partes do próprio corpo, e componentes da própria vida psíquica, percepções, pensamentos, afetos, nos surgem como alheios e não pertencentes ao Eu; outros, em que se atribui ao mundo externo o que evidentemente surgiu no Eu e deveria ser reconhecido por ele. Logo, também o sentimento do Eu está sujeito a transtornos, e as fronteiras do Eu não são permanentes.” [p. 16]

Apresento a seguir um recorte clínico em que um casal vive uma alternância constante entre estados de apaixonamento e estados de profundo mal-estar.

Júlia e Ramón estavam juntos fazia alguns anos; conviviam mal, com muitas brigas e agressões mútuas. Ambos eram bem-sucedidos na vida profissional e faziam questão de ter autonomia e independência um do outro, muitas vezes com movimentos de hiperdiscriminação do que pertenceria a cada um, isto é, demonstrando necessidade de demarcar claramente o próprio território: isso é meu, isso é seu. Às vezes falavam em se separar, às vezes pensavam em prosseguir com o "projeto bebê".

Havia um clima extremamente tenso entre os dois, cada um querendo determinar para o outro como as coisas deveriam ser, sendo que ambos esperavam que eu fosse uma espécie de juíza, pronta a dar o veredicto sobre quem estava a razão. Observei que os dois, cada um a seu modo, possuíam ideias importantes a respeito do que viviam. Entretanto, tratava-se de uma conversa de surdos. O conflito podia aparecer como uma luta de poder expressa através de gestos de "retaliação", de "vingança", de "dar o troco", num circuito que se retroalimentava o tempo todo. 
Ambos tinham dificuldades de se dar conta de que o outro não correspondia àquilo que imaginava, e essa turbulência tinha como efeito borrar as diferenças. A frequência e a intensidade dos embates muitas vezes mobilizaram neles sentimentos de desânimo e cansaço, como se dissessem: Não, não adianta nada, não tem jeito...

A metabolização das diferenças presentes no conflito intersubjetivo é sempre difícil, pois implica entrar em contato com o fato de que, no enamoramento, a busca da fusão absoluta aproxima-se de estados de profundo desamparo.

Ao longo do trabalho com Júlia e Ramón, percorri um território árido, no qual reconheci em mim um grande desconforto que se manifestou sob a forma de fortes sentimentos de desalento e, sobretudo, de paralisia. A comunicação que se fazia com palavras se apresentava como uma forma de ação; o que era dito acabava por ser usado como uma espécie de ataque de um contra o outro, existindo assim uma espécie de esterilidade através das palavras. No decorrer dos atendimentos, a dinâmica do casal foi tornando claro como os dois faziam para ir se esterilizando mutuamente.

Essa esterilidade se manifestava também na relação comigo e teve repercussão direta em minha escuta; em muitos momentos, surgiam-me impressões de maneira esparsa e eu constatava em mim uma dificuldade de ligar uma ideia e outra, uma impossibilidade de tecer um sentido.

Certo dia, em uma dessas sessões turbulentas, Ramón se lembrou de uma escultura que tinha visto recentemente: dois corpos muito próximos um do outro, de cada um deles saindo uma espécie de feixe de tentáculos. Julia disse: Dois corpos frente a frente, tão perto que é quase como se fossem um...

Lembrei-me logo dessa imagem, eu a tinha visto em mais de uma exposição. Tratava-se de O Impossível, obra de 1940 de Maria Martins [1894-1973]. Vemos dois corpos um de frente para o outro, como se estivessem de joelhos, e, no lugar do que seriam os braços e a cabeça, brotam tentáculos - são corpos "ouriçados", desejando-se e estranhando-se simultaneamente. Parece haver uma circularidade entre masculino e feminino; o corpo maior é fino, comprido, fazendo referência a seios, e o outro é menor, com formas arredondadas. As extremidades de ambos quase se tocam, com seus 
tentáculos que se atraem e se repelem. O impossível é a própria impossibilidade de um encontro perfeito, absoluto.

Essa imagem põe em evidência o conflito existente entre a fusão e o registro das diferenças, acentuando a presença de ansiedades persecutórias. Os dois corpos, como se dotados de garras ou como ouriços de bocas dentadas, fariam referência ao amor canibal? Ao engolfamento? À tentativa de controlar e submeter o outro? Aparece a luta entre o eu e o outro, luta em que a prevalência de um ameaça a existência do oponente. Estariam ambos em perigo? Um pacto mortífero transforma a fusão amorosa em destruição da alteridade? Seria possível construir um vínculo capaz de preservar a alteridade de cada um?

A tolerância à existência do outro, à alteridade, implica um intenso e árduo trabalho psíquico, implica reelaborar imagens de si e do outro, assim como do vínculo. Análise é um processo de descobrimento do inconsciente do paciente, mas também inclui o analista. Na intimidade da clínica, aparece hospitalidade para acolher o que brota de um para o outro. No acontecimento sentido, surge um espaço entre nós, gradativamente torna-se possível uma construção conjunta, uma criação compartilhada de imagens, metáforas do inconsciente vincular em curso, gerando novos sentidos.

As novas formas de casal e de família se multiplicam na sociedade contemporânea, constituindo um terreno movediço que solicita do analista reflexões difíceis e complexas no decorrer do atendimento. $\mathrm{Na}$ experiência clínica, observamos um empobrecimento da capacidade simbólica e, muitas vezes, atuações com finalidade de evitação de dor e sofrimento. Surge por vezes a necessidade de trabalhar simultaneamente com conflitos pontuais e com aquilo que está em processo de se constituir, ou seja, é preciso trabalhar também com aquilo que subjaz aos conflitos. Aparecem estados-limite, fissuras nos vínculos de sustentação, o não constituído, o não simbolizado. O trabalho analítico se volta então para o que ainda não chegou a existir.

Uma sociedade em intenso processo de transformação demanda do analista aguda sensibilidade para viver o que se apresenta, para tolerar, conter e aprender com a experiência emocional do acontecimento na sessão, em busca de sentidos que implicam também construções provisórias e abertas a transformações. 
A disposição para o desconhecido, para as incertezas e contradições (que coexistem) possibilita captar a realidade psíquica, permite apreensões e aproximações seja na dimensão intrassubjetiva (mundo interno), seja na dimensão intersubjetiva, as quais estão em contínua dialética.

$\mathrm{Na}$ clínica, a atitude analítica, a pessoa do analista e o referencial teórico-clínico oferecem instrumentos para lidar com o funcionamento inconsciente das relações intersubjetivas.

Kaës (2007) propõe: "Não há um sem o outro, nem sem o vínculo que os une e contém". O psiquismo é considerado aberto, extenso, em continuidade com o outro e o mundo externo, sociocultural. Nessa relação os dois se interdeterminam e se constituem, gerando um inconsciente vivo e processos de subjetivação.

A metáfora da fita de Moebius, retomada por Spivacow (2011), ilustra a ausência de oposição entre interior e exterior: são dois espaços contínuos, um remetendo ao outro sem que possamos identificar a fronteira entre eles (p. 63).

A dinâmica intersubjetiva expressa-se através do discurso conjunto correspondente à cadeia associativa produzida por um casal ou família durante a sessão. A bidirecionalidade inconsciente é a qualidade do psiquismo pela qual os participantes de um vínculo sofrem modificações recíprocas tanto em nível consciente como inconsciente (Spivacow, 2015).

No trabalho com famílias e casais, a dinâmica vincular apresenta-se em diferentes níveis de desenvolvimento emocional: vivências primitivas de estados não integrados, com intensas identificações projetivas entre os membros, transitando por estados de integração/desintegração (vínculos internos) e vínculos externos. Em outra dimensão, a realidade psíquica característica da situação vincular traz alianças inconscientes estruturantes e defensivas, pactos e conluios. Ambas as dimensões se alternam e se compõem em um equilíbrio instável, indo do território narcísico à tolerância, à diferença e à alteridade. 
A análise, mediante o acolhimento de vivências inconscientes do mundo primitivo, favorece o aprender com a experiência emocional e a produção de metáforas, de simbolizações relacionadas à realidade psíquica vincular, o que pode possibilitar transformações e expansão psíquica nos vínculos e nas subjetividades.

\section{Referências}

Ariès, P. (1978). História social da família e da criança. Rio de Janeiro: Guanabara.

Bion, W. (1975). Experiências com grupos. Rio de Janeiro: Imago.

Bauman, Z. (2004). Amor líquido: Sobre a fragilidade dos laços humanos. Trad. Carlos Alberto Medeiros. Rio de Janeiro: Zahar.

Bauman, Z. (1998). O mal-estar da pós-modernidade. Rio de Janeiro: Zahar. Trad. Claudia M. G. Lopes da Costa e Mauro G. Lopes da Costa.

Cypel, L. R. C. (2012). Psicanálise dos vínculos de família e casal e a subjetivação do indivíduo nos tempos atuais. In: I. C. Gomes, M. I. A. Fernandes, Levisky, R. B., orgs. Diálogos psicanalíticos sobre família e casal. São Paulo: Zagodoni.

Cypel, L.R.C.2017. Reflexões sobre a interpretação na clínica contemporânea de família e casal in Revista Brasileira de Psicanalise V.51, n.2

Maria Martins. In: Enciclopédia Itaú Cultural de Arte e Cultura Brasileiras. São Paulo: Itaú Cultural, $2018 . \quad$ Disponível em http://enciclopedia.itaucultural.org.br/pessoa21390/maria-martins. Verbete da Enciclopédia. ISBN: 978-85-7979-060-7; O Impossível. Disponível em $<$ http://enciclopedia.itaucultural.org.br/obra35220/o-impossivel $>$ [acesso em 25.julho.2018]. Verbete da Enciclopédia. ISBN: 978-85-7979-060-7

Freud, S. (1930). O mal-estar na civilização. In: S. Freud, Freud (1930-1936). O malestar na civilização e outros textos. Obras completas. V. 18. Org. e trad. Paulo César de Souza. São Paulo: Companhia das Letras, 2010.

Justino, M. J. (2011). Maria Martins: uma poética do desejo. Escola de Música e Belas Artes do Paraná/Associação Nacional de Pesquisadores em Artes Plásticas (Anpap). 
Disponível em http://www.anpap.org.br/anais/2011/pdf/chtca/maria_jose_justino.pdf [acesso em 25.julho.2018].

Kaës, R. (2016). As alianças inconscientes. São Paulo: Ideias e Letras.

Kaës, R. (2011). Um singular plural: a psicanálise à prova do grupo. São Paulo: Loyola.

Kaës, R. (1996). Introducción al concepto de trasmisión psíquica en el pensamiento de Freud. In: R. Kaës, H. Faimberg, M. Enriquez, Trasmisión de la vida psíquica entre generaciones. Buenos Aires: Amorrortu.

Spivacow, M. A. (2015). Uma ferramenta do nosso arsenal terapêutico: a terapia psicanalítica de casal. Calibán: Revista Latinoamericana de Psicoanálisis - As ferramentas do analista, v. 13, n. 1, p. 64-82.

Spivacow, M. A. (2012). La clínica psicoanalítica con parejas. Buenos Aires: Lugar Editorial.

Spivacow, M. A. (2011). La pareja en conflicto: aportes psicoanalíticos. Buenos Aires: Paidós.

Trachtenberg, A. R. C. et al. (2013). Transgeracionalidade: de escravo a herdeiro: um destino entre gerações. Porto Alegre: Sulina. 